\title{
(2019) Optimal Threshold for Selection of Candidates in Multi-Winner Elections
}

\author{
By John Lawrence
}

\section{$\underline{\text { Abstract }}$}

We devise a method for political and economic decision making that's applicable to the optimal selection of multiple alternatives from a larger set of alternatives. This method could be used, for example, in the selection of a committee or a parliament. The method combines utilitarian voting with approval voting and sets an optimal threshold above which an individual voter's sincere ratings are turned into approval style votes. Those candidates above threshold are chosen in such a way as to maximize the individual's expected utility for the winning set. We generalize range/approval hybrid voting which deals with a single member outcome to the case of multiple outcomes. The political case easily generalizes to the economic case in which a commodity bundle is to be chosen by each individual from an available set which is first chosen from a larger set by the amalgamation of the individual choosers' inputs. As the set made available gets larger, the individual voter or chooser is more likely to gain greater utility or satisfaction because more of their above threshold candidates will be included in the winning set.

\section{$\underline{\text { Introduction }}$}

In Social Choice and Individual Values, Kenneth Arrow (1951) wrote', "In a capitalist democracy there are essentially two methods by which social choices can be made: voting, typically used to make 'political' decisions, and the market mechanism, typically used to make 'economic' decisions." He goes on to say, "The methods of voting and the market ... are methods of amalgamating the tastes of many individuals in the making of social choices." Initially, Arrow does not distinguish between political and economic systems claiming that both are means of formulating social decisions based on individual inputs. Arrow then purports to show that there is no rational way to make social decisions based on the amalgamation of individual ones thus ruling out welfare economics or economic democracy and also direct political democracy. The dichotomy between political and economic systems remains with the implication being that representive democracy and capitalist economics are the best systems that can be devised.

Despite Arrow's tautological conclusions, it has been shown by Aki Lehtinen ${ }^{2}$ that strategic voting behavior which violates one of Arrow's conditions is actually beneficial, and, therefore, one of Arrow's conditions is not normatively acceptable. Lehtinen asserts: 
"This means that, while Arrow's theorem and the Gibbard-Satterthwaite ${ }^{3,4}$ [theorem] are logically impeccable, they fail to have the devastating consequences for democracy that have sometimes been attributed to them."

Arrow sets up the problem so that each individual voter or chooser orders all alternatives and then society is required to come up with an ordering that is best according to some criteria. He states "in the theory of elections, the alternatives are candidates. ... In the theory of consumer's choice each alternative would be a commodity bundle...". Insofar as voting is concerned, there will be winners and losers. As Smith ${ }^{5}$ has pointed out, we don't need to be concerned about the ordering of the losers. "Nobody cares about rank-ordering the losers! We care about finding the winner." Or winners in the case of multi-winner elections. However, the method constructed in this paper actually inputs information from voter/choosers from which a complete individual ordering can be derived and outputs information from which a complete social ordering can be derived including ordering of the losers!

Traditional theory assumes that only one candidate or, in the economic case, commodity bundle, is to be selected. Recently, there have been a number of papers on multi-winner elections ${ }^{6,7,8,9,10,11}$. These types of analyses could also apply to the selection of a group of commodity bundles from a larger set. Traditional approval voting ${ }^{12}$ lets the voter choose more than one candidate, but society chooses only one to fill the elected position. In this paper we assume that multiple candidates can be elected from multi-winner districts so that the voter can have a voice in choosing more than one candidate out of the set of available candidates, and there are multiple positions to be filled. Although members elected to a multi-winner district are usually considered as equals, this method could produce rankings as well based on the final vote tallies.

The voting method discussed in Aziz et. al. requires each voter to input the number of his most favored candidates equal to the committee size. This is called bloc voting. Restrictions are then placed on the output of the election. Elkind et. al. considers bloc rules "that asks each voter to specify her favourite committee of $\mathrm{k}$ candidates and selects $\mathrm{k}$ candidates that were mentioned more frequently than others;..."

Fishburn and Pekeč discuss procedures wherein each voter inputs their favorite committee of size $\mathrm{m}$ and the selection method consists of putting constraints on the output which consists of a committee chosen by society of size m. "The key feature of our procedure is that the aggregation rule is defined to capture voters' preferences over admissible committees, instead of constructing a winning committee based on voters' preferences over individual candidates." Fishburn contrasts this method with the method of approval voting in which each voter submits a list of his $\mathrm{m}$ favorite candidates, and the 
winners are those with the $\mathrm{m}$ highest vote totals. They state: "The basic premise of the work presented here is that aggregating preferences over subsets could and should take into account actual preferences over subsets, rather than choosing a subset by combining top singleton choices stemming out of some aggregation preferences over single alternatives."

Each of the writers mentioned above assumes that the voter/chooser inputs an m-sized bloc from which a winning m-sized bloc is chosen. In contrast our method sets an optimal threshold for each individual voter above which a varying number of candidates can be approved of in such a way as to maximize the power of each individual's vote. The final tally for each candidate is added up and those candidates with the $\mathrm{m}$ highest vote totals are declared the winning committee. The problem with the above systems in which an m-sized bloc is submitted by each individual voter is that there is no consideration of candidates other than the $\mathrm{m}$ favorites which, however, might be more universally liked than those in the m-sized final output.

Reshef Meir et. al. are concerned with the manipulability of a multi-winner voting scheme. They write: "The Gibbard-Satterthwaite theorem asserts that any voting rule which cannot be manipulated must be a dictatorship, i.e., there is one voter who dictates the outcome of the election. A considerable body of work has been devoted to circumventing this theorem." In this paper we assume that each voter is interested in maximizing the utility of the winning set for him or her. We construct the voting procedure in such a way that each voter's input is such as to maximize that voter's individual expected utility so that he or she has no incentive to manipulate which would only decrease the utility of the winning set for him or her. If the manipulation is applied not by random individuals but universally by society itself in the interest of each individual, then Gibbard-Satterthwaite may not apply. This is a subject for further study.

To state the problem formally, let $\mathrm{S}$ be the set of all political candidates (workcommodity bundles). Let $\mathrm{W}$ be the set chosen by society based on individual inputs. $\mathrm{W} \subset \mathrm{S} .|\mathrm{W}|<|\mathrm{S}|$. We assume that voters (consumers) vote using approval voting (AV) methods and then society generates the set $\mathrm{W}$ based on the previously decided size of $\mathrm{W}$. The top $|\mathrm{W}|$ vote getters would comprise that set which we call the "winning set". We devise a rational method for determining which candidates (work-commodity bundles) should be given AV style votes by each individual voter (worker-consumer) based on their individual sincere preference ratings.

We continue with the understanding that, in order to simplify the discussion and unless otherwise stated, voters can be replaced with worker-consumers, candidates can be replaced with work-commodity bundles and vice versa. 


\section{Utilitarian and Approval Voting}

As inputs Arrow insists on orderings instead of more nuanced cardinal input information in order to avoid interpersonal comparisons. However, voting, ergo facto, is a process in which all are assumed interpersonally comparable in terms of one person, one vote. We assume the same rationale for economic decision making. Lehtinen ${ }^{13}$ asserts: "If the principle is justified by appealing to interpersonal comparisons, the weight of each individual in determining the social optimum ought to be the same. The justification of the one-man-one-vote principle derives here from the claim that, a priori, each individual ought to have equal weight in determining the will of the people. It follows that each individual ought to have the same opportunity to affect the outcome of a voting process. Another way to look at the issue is to note that since the one-man-one-vote principle is violated only if we know that some voters have a legitimate claim to more than equal influence on the voting outcome, when there are no such reasons to violate the principle, we should also assume that each voter's utility is measured with the same scale."

We take a utilitarian approach first developed by Harsanyi ${ }^{14}$ in 1955 . Later Risse ${ }^{15}$ extended Harsanyi's Utilitarian Theorem.

The method considered here involves placing a threshold in an optimal manner such that all candidates with corresponding sincere utilities above that threshold are given positive approval style votes. Candidates with corresponding utilities below threshold are given negative approval style votes. This manner of approval voting is considered sincere with respect to Niemi's ${ }^{16}$ definition of sincere approval voting. As Niemi points out, “... under AV sincere voters are still left with multiple strategies to consider." Not all strategy is considered insincere.

Regarding Arrow's condition, Independence of Irrelevant Alternatives (IIA), Lehtinen has shown that IIA is moot if strategy is involved which is the case in this paper. "However, from the utilitarian and thus welfarist point of view, strategic voting is desirable rather than undesirable under most commonly used voting rules." $\mathrm{Cox}^{17}$ has also considered strategic voting in multi-winner districts. We assert that the voting system considered here is both strategic and sincere. Some individuals may gain an advantage, however, unless the strategy is applied universally by society itself and not left up to individual voters who may or may not apply the strategy incorrectly.

The only relevant point to be made regarding IIA is that, if a candidate drops out from or is added to the set $\mathrm{S}$, the threshold might change. Once the candidate set is finalized, the 
threshold will not vary due to the fact that candidate ratings using sincere cardinal information are assumed to remain the same for each voter regardless of candidate dropouts or add-ons. For drop-outs or add-ons, the threshold would need an adjustment and would just have to be recomputed. The cardinal preference ratings of the voters regarding other candidates is assumed not to change.

Binmore $^{18}$ also assumes that, even for a welfare economy or economic democracy, voting methods are used, and hence each individual chooser or voter is allocated the power of one vote thus equalizing all interpersonal comparisons.

Hillinger ${ }^{19}$ has also made the case for utilitarian voting:

"There is, however, another branch of collective choice theory, namely utilitarian collective choice, that, instead of fiddling with Arrow's axioms, challenges the very framework within which those axioms are expressed. Arrow's framework is ordinal in the sense that it assumes that only the information provided by individual orderings over the alternatives are relevant for the determination of a social ordering. Utilitarian collective choice assumes that individual preferences are given as cardinal numbers; social preference is defined as the sum of these numbers. The fact that voting procedures are cardinal suggests that cardinal rather than ordinal collective choice theory should be relevant."

Hillinger $^{20}$ advocates Evaluative Voting (EV) in which the voter assigns a value to each candidate. For example, EV-3 assigns one of the values $(-1,0,+1)$, and then the values are summed over all candidates to determine the winner. Lorinc Mucsi ${ }^{21}$ also supports Hillinger in his advocacy for EV-3 which allows the voter to vote for, against or remain neutral regarding each candidate. The problem with approval voting, which Hillinger claims to ameliorate, is what to do with the candidates that are neither strongly approved of or strongly disapproved of i.e. those in the middle. Hillinger assigns these candidates a value of zero. $\mathrm{He}^{22}$ asserts:

"Another criticism of $A V$, is due to Lawrence Ford, chair of the mathematics department, Idaho State University, ... :

One big flaw [of $A V$ ] is that most voters are fairly positive of their favorites and fairly positive of those they hate, but wishy-washy in the middle. If they choose randomly for or against approval in that middle range, the whole election can become random.

Directed against $A V$, this criticism has some validity because under $A V$, not to approve a 
candidate is equivalent to being against him. This puts the voter in a bind of having to be for or against, when in fact he lacks the relevant information for [such] a judgment."

The use of an optimal threshold to determine which candidates get an approval style vote of +1 and which get an approval style vote of -1 clears up one of the criticisms of approval voting regarding what to do about candidates that a voter is wishy washy about. All those above threshold get a +1 vote; all those below get a -1 vote. The only ones who would get a 0 vote would be those that fell directly on or close to the threshold.

Lehtinen ${ }^{23}$ concludes that Arrow's Impossibility Theorem is not relevant in the final analysis: "Arrow's impossibility result and the closely related theorems given by Gibbard and Satterthwaite are unassailable as deductive proofs. However, we should not be concerned about these results because their most crucial conditions are not justifiable. Fortunately, we know that strategy-proofness is usually violated under all voting rules and that IIA does not preclude strategic voting." Gendin ${ }^{24}$ also considers Arrow's Impossibility Theorem to be invalid.

The theory advanced herein results in approval voting in the sense that individual cardinal inputs are converted to approval style votes. Historically, approval voting is geared to selecting one candidate from a single member district. In that case it has been shown that votes should be cast for all candidates who are above average with respect to a voter's cardinal rating scale. Smith ${ }^{25}$ proves the following: "Mean-based thresholding is optimal range-voting strategy in the limit of a large number of other voters, each random independent full-range." Range voting is similar to utilitarian voting. Lehtinen ${ }^{23}$ has used expected utility maximising voting behavior to indicate which candidates should be given an approval style vote in single member districts. He agrees with Smith that an approval style vote of +1 should be given to all candidates for whom the utility exceeds the average for all candidates. All others would get an AV vote of zero. For single member districts then the optimal threshold is placed at the mean of the sincere ratings for each individual.

An undesirable aspect of most voting systems is Bayesian regret. Bayesian regret is the difference in overall social utility between a voting system that maximizes social utility and the voting system under consideration. Smith ${ }^{26}$ has measured Bayesian regret for several different voting systems via computer modeling. He has shown ${ }^{27}$ that range (or the renamed score) voting is the best system with regards to Bayesian regret for single member districts. With regard to Bayesian regret, the stance taken here is that it is the price to be paid for a voting system which is stable in the sense that everyone gets the benefit of an optimal strategy which can be computed by the individual voter or can be provided by the system itself in such a way that no one can gain an advantage by 
misrepresenting their sincere preference ratings. If done in this way, it negates the advantage of strategizing by individuals and equalizes the benefits of strategizing for all voters. By doing so two things are accomplished: 1) there is nothing to be gained by an individual voter in strategically misrepresenting their sincere preferences so that each voter has an incentive to vote sincerely, utilitarian style, using their true preference ratings, and 2) each voter will be assured that they will gain the advantages of an optimal strategy.

\section{Voting With One Outcome}

Strategic considerations lead to applying a formula to each individual's sincere preference ratings in order to maximize the expected utility of the outcome for that individual. Smith states: "A 'rational voter', by definition, votes in such a way as to maximize the expected utility of the election result." For this paper all ratings greater than the individual's average rating are changed to +1 , and all ratings less than the average are changed to -1 . This is equivalent to placing a threshold at the mean of the preference ratings and adjusting the ratings of every sincere preference above the threshold to +1 and every rating below the threshold to -1 . Preference ratings falling right on or near the threshold can be given a 0 vote similar to Hillinger's preferred EV-3 voting method.

Finally, the approval style votes for each candidate are summed over all voters, and the candidate with the most votes is declared the winner.

We will only consider the case in which individual strategy occurs without knowledge of statistical information regarding other voters. The more general case in which knowledge of the sincere preferences of other voters is taken into account before strategizing is beyond the purview of this paper. Lehtinen considers a case in which the statistics regarding other voters are taken into account.

\section{Enlarging the Winning Set}

For multi-winner districts, the threshold needs to be adjusted upwards from just below the mean utility as will be shown. We use the same idea of expected utility maximising to make a decision as to where to place the threshold above which all candidates will get an approval style vote of +1 . Those below threshold will get an approval style vote of -1 , and those located right on or close to the threshold will get a vote of 0 . Brams and Fishburn state ${ }^{28}$ : "Because approval of a less-preferred candidate can hurt a morepreferred candidate, the voter still faces the decision under AV of where to draw the line between acceptable and nonacceptable candidates." This paper resolves that dilemma. 
The threshold will vary depending on the number of members to be chosen, and it will vary for each individual voter.

In a multi-winner district, the voting procedure will select a number of candidates, the set,W, from a larger set of candidates, S. From an economic viewpoint, the choosing procedure can be thought of as first deciding which commodity bundles should be made available (the set $\mathrm{W}$ ) from a larger set of possible bundles (the set S). Each workerconsumer then selects one commodity bundle out of those that are available according to some secondary procedure.

Let $\mathrm{m}=|\mathrm{W}|<|\mathrm{S}|$ represent the size of the winning set of candidates. In a single member district, for example, $\mathrm{m}=1$. When $\mathrm{m}>1$, as in a multi-winner district, it is assumed that each voter would seek to maximize the utility for them of the set, $\mathrm{W}$. The utility of the winning set for the individual voter can be computed from that individual's sincere preference ratings. The social utility would be the summation over all voters of their utilities for the winning set. Bayesian regret would be the difference between this and the maximum social utility computed over all possible winning sets.

Let's examine an individual citizen's preference ratings which represent a specification of utilities over the candidates with each utility corresponding to a position on the preference rating scale which we choose, without loss of generality, to be a real number between -1 and +1 . Each individual voter associates each candidate with a particular utility on that scale. For sincere utilitarian voting, the greater the indicated utility, the greater the probability that a particular candidate will be elected due to that individual voter's rating alone since utilities for a particular candidate are additive over all voters.

The greater the utility for a particular candidate, the more likely it is that that candidate will also get an approval style +1 vote in the case of approval or EV $-3^{10}$ voting. For each value of $\mathrm{m}$ we place the threshold such that the expected utility for the set of candidates with preference ratings greater than threshold is a maximum. There is a different threshold for each individual voter.

Let's assume that, for a particular individual, there is a preference rating scale composed of real numbers from -1 to +1 . Let $\mathrm{T}$ represent the real number threshold, $-1 \leq \mathrm{T} \leq+1$.

Let $\mathrm{C}$ be the set of all candidates, $\mathrm{c}_{\mathrm{i}}$ be a particular candidate with associated utility, $\mathrm{u}_{\mathrm{i}}, \mathrm{U}$ be the set of utilities corresponding to all candidates, $U_{a}$ be the set of utilities above threshold and $\mathrm{U}_{\mathrm{b}}$ be the set of utilities below threshold. Let $\mathrm{C}_{\mathrm{a}}$ be the set of candidates above threshold and $\mathrm{C}_{\mathrm{b}}$ be the set of candidates below threshold. Let $\mathrm{u}_{\mathrm{a}}$ be the sum of utilities above threshold and $u_{b}$ be the sum of utilities below threshold. Let the number of 
candidates above threshold be $n_{a}$. Let $n_{b}$ be the number of candidates below threshold so that $\mathrm{n}=\mathrm{n}_{\mathrm{a}}+\mathrm{n}_{\mathrm{b}}=$ total number of candidates with associated utilities.

We must distinguish between the utilities of the particular individual's preference rating scale before voting and their utilities for the set $\mathrm{W}$ which is determined by the voting process. Let $\mathrm{V}$ be a random variable which represents the utility of the winning set for the particular individual under consideration.

$$
\mathbf{E}(\mathbf{V})=\sum_{\mathrm{i}=1}^{\mathrm{n}} \mathbf{p}_{\mathrm{i}} \mathbf{u}_{\mathrm{i}}
$$

Where $\mathrm{p}_{\mathrm{i}}$ represents the probability of candidate $\mathrm{i}$ with associated utility $\mathrm{u}_{\mathrm{i}}$ being in the winning set. This can also be written as

$$
\mathbf{E}(\mathbf{V})=\sum_{\mathrm{i}=1}^{\mathbf{n}_{\mathrm{a}}} \mathbf{p}_{\mathrm{i}} \mathbf{u}_{\mathrm{i}}+\sum_{\mathrm{j}=1}^{\mathrm{n}_{\mathrm{b}}} \mathbf{p}_{\mathrm{j}} \mathbf{u}_{\mathrm{j}}
$$

where the first term is the expected value of the utility for the set of candidates above threshold and the second term is the expected value of the utility for the set of candidates below threshold.

We are interested in placing the threshold in such a way as to maximize the expected utility above threshold:

$$
\mathbf{E}\left(\mathbf{V}_{\mathrm{a}}\right)=\sum_{\mathrm{i}=1}^{\mathrm{n}_{\mathrm{a}}} \mathbf{p}_{\mathrm{i}} \mathbf{u}_{\mathrm{i}}
$$

where Va is a random variable representing the utility above threshold.

We assume no knowledge of statistics regarding outcomes of the election process, other voters' preferences or polling data. Therefore, the probability of any particular candidate being in the winning set is the same for all candidates. If reliable polling information is available, the probabilities might be different for some or all of the candidates, but that is beyond the scope of this paper.

We define $\mathrm{p}_{\mathrm{i}}$ as follows: 


\section{$\left.\mathrm{p}_{\mathrm{i}}=\mathrm{P}\left[\mathrm{c}_{\mathrm{i}} \in \mathrm{W}|| \mathrm{W} \cap \mathrm{C}_{\mathrm{a}} \mid \geq 1\right] \mathrm{P}|| \mathrm{W} \cap \mathrm{C}_{\mathrm{a}} \mid \geq 1\right]$}

This can be interpreted as the probability that candidate $i$ is in the winning set given that one or more above threshold candidates are in the winning set times the probability that one or more above threshold candidates are in the winning set.

The probability of the $i^{\text {th }}$ candidate being in the winning set given that one or more above threshold candidates are in the winning set is $1 / \mathrm{n}_{\mathrm{a}}$. The probability of one or more above threshold candidates being in the winning set can be expressed by the hypergeometric function. The hypergeometric function can be modeled as a ball and urn problem containing white and black balls. The candidates above threshold are identified with white balls and the candidates below threshold are identified with black balls. We posit a "picker" that picks balls one at a time out of the urn without replacement and places the balls in the winning set.

The mathematics for this is the following:

$$
\mathbf{p}^{\prime}=\frac{\left(\begin{array}{c}
\mathbf{n}_{\mathbf{a}} \\
\mathbf{k}
\end{array}\right)\left(\begin{array}{l}
\mathbf{n}-\mathbf{n}_{\mathbf{a}} \\
\mathbf{m}-\mathbf{k}
\end{array}\right)}{\left(\begin{array}{l}
\mathbf{n} \\
\mathbf{m}
\end{array}\right)}
$$

\section{where $p^{\prime}$ equals the probablity of $k$ above threshold candidates out of $m$ picks.}

The hypergeometric distribution is a discrete probability distribution that describes the probability of $\mathrm{k}$ successes in $\mathrm{m}$ draws, without replacement, from a finite population of size $n$ containing exactly $n_{a}$ successes, wherein each draw is either a success or a failure. A success is identified as picking one of the candidates above threshold (a white ball) to be in the winning set. $\mathrm{k}$ is the number of white balls in the winning set picked out of $\mathrm{m}$ draws, $\mathrm{k} \leq \mathrm{n}_{\mathrm{a}}$.

$p($ at least one above threshold candidate is selected $)=p_{i}=$

1 - $\mathbf{p}^{\prime}$ (every candidate selected is below threshold) 


$$
\begin{aligned}
& =1-\frac{\left(\begin{array}{c}
\mathbf{n}_{\mathrm{a}} \\
\mathbf{0}
\end{array}\right)\left(\begin{array}{c}
\mathbf{n}-\mathbf{n}_{\mathrm{a}} \\
\mathbf{m}-\mathbf{0}
\end{array}\right)}{\left(\begin{array}{c}
\mathbf{n} \\
\mathbf{m}
\end{array}\right)} \\
& =1-\frac{\left(\mathbf{n}-\mathbf{n}_{\mathrm{a}}\right)}{\left(\begin{array}{c}
\mathbf{n} \\
\mathbf{m}
\end{array}\right)} \\
& =1-\frac{(\mathbf{n}-\mathbf{m})(\mathbf{n}-\mathbf{m}-\mathbf{1}) \ldots\left(\mathbf{n}-\mathbf{n}_{a}-\mathbf{m}+\mathbf{1}\right)}{\mathbf{n}(\mathbf{n}-\mathbf{1}) \ldots\left(\mathbf{n}-\mathbf{n}_{a}+\mathbf{1}\right)}
\end{aligned}
$$

In general we have

$$
p_{i}=1-\left[1-\left(n_{a} / n\right)\right]\left[1-n_{a} /(n-1)\right] \ldots\left[1-n_{a} /(n-i)\right] \ldots\left[1-n_{a} /(n-m+1)\right]
$$

for $\mathbf{m}<\mathbf{n}-\mathbf{n}_{\mathbf{a}}-\mathbf{1}$

Since $\mathbf{p}_{\mathbf{i}}$ is the same for all $\mathbf{i}$ above threshold,

$$
\text { Let } \mathrm{p}_{\mathrm{i}}=\mathrm{p} \forall \mathrm{i} \text { above threshold }
$$

Therefore, the expected value of the utility associated with above threshold candidates for a particular individual voter is the following:

$$
\mathbf{E}\left(\mathbf{V}_{\mathrm{a}}\right)=\mathbf{p}\left(\frac{\mathbf{1}}{\mathbf{n}_{\mathrm{a}}}\right) \sum_{\mathrm{i}=1}^{\mathbf{n}_{\mathrm{a}}} \mathbf{u}_{\mathrm{i}}
$$

Therefore, $\mathbf{E}\left(\mathbf{V}_{\mathbf{a}}\right)=\mathbf{p}\left(\mathbf{u}_{\mathbf{a}} / \mathbf{n}_{\mathbf{a}}\right)$. 
We want to determine where to place the threshold so as to maximize the expected utility of those candidates above threshold for the individual voter under consideration. To simplify the discussion, let us assume, as an example, that the values of the possible utilities are uniformly spread from -1 to +1 in accordance with the spacing,

$$
\frac{2}{(n-1)}
$$

and that there is one candidate corresponding to each utility. The results are easily extended to a more generalized solution since they only depend on the sum of utilities above threshold, the number of candidates above threshold, the total number of candidates and the size of the winning set.

We do the computations for every possible threshold to determine which threshold is best i.e. which threshold results in the maximum value of expected utility of the winning set for the individual voter under consideration. All candidates above threshold will have their votes increased to +1 , and those below threshold will be decreased to -1 .

Candidates whose utilities fall exactly on or close to the threshold will be set to zero. The results for all candidates will then be tallied over all voters. Maximizing individual voter satisfaction or utility has to do with the correct placement of the threshold for each individual.

Let's do an example with $\mathrm{m}=1$ which should check with the previous result from $\mathrm{Smith}^{16}$ for range/approval hybrid voting.

$$
\mathrm{p}=1-\frac{\mathrm{n}-\mathrm{n}_{\mathrm{a}}}{\mathrm{n}}
$$

Expected value of utility $=\mathbf{E}\left(V_{\mathbf{a}}\right)=\mathbf{p}\left(\mathbf{u}_{\mathbf{a}} / \mathbf{n}_{\mathbf{a}}\right)=\left(\mathbf{n}_{\mathbf{a}} / \mathbf{n}\right)\left(\mathbf{u}_{\mathbf{a}} / \mathbf{n}_{\mathbf{a}}\right)=\mathbf{u}_{\mathbf{a}} / \mathbf{n}$

If we place the threshold just under $-1, \mathrm{n}_{\mathrm{a}}=\mathrm{n}, \mathrm{p}=1, \mathrm{u}_{\mathrm{a}}=0, \mathrm{E}\left(\mathrm{V}_{\mathrm{a}}\right)=0$.

If we place the threshold just under +1 ,

$\mathrm{n}_{\mathrm{a}}=1, \mathrm{u}_{\mathrm{a}}=1, \mathrm{p}=1 / 9$ and $\mathrm{E}\left(\mathrm{V}_{\mathrm{a}}\right)=1 / 9$.

When the threshold is just over $+1, \mathrm{n}_{\mathrm{a}}=0, \mathrm{u}_{\mathrm{a}}=0, \mathrm{p}=0$. We define the value of $\mathrm{E}\left(\mathrm{V}_{\mathrm{a}}\right)$ to be 0 at a utility of $1+(2 / n-1)$. In general, for $n$ large, $E\left(V_{a}\right)$ can be made to be zero for a value of utility equal to $1+\Delta$ with $\Delta$ being arbitrarily small. 
Let's do an example for the following data set:

$\mathrm{u}_{\mathrm{i}} \in\{-1,-3 / 4,-1 / 2,-1 / 4,0,1 / 4,1 / 2,3 / 4,1)$

For threshold under $-1: \quad \mathrm{p}=1, \quad \mathrm{u}_{\mathrm{a}} / \mathrm{n}_{\mathrm{a}}=0$,

$\mathrm{E}\left(\mathrm{V}_{\mathrm{a}}\right)=0$

For threshold under $-3 / 4: \quad \mathrm{p}=8 / 9, \quad \mathrm{u}_{\mathrm{a}} / \mathrm{n}_{\mathrm{a}}=(1)(1 / 8), \quad \mathrm{E}\left(\mathrm{V}_{\mathrm{a}}\right)=1 / 9$

For threshold under $-1 / 2: \quad p=7 / 9, \quad u_{a} / n_{a}=(7 / 4)(1 / 7)=1 / 4, \quad E\left(V_{a}\right)=7 / 36$

For threshold under $-1 / 4: \quad p=6 / 9, \quad u_{a} / n_{a}=(9 / 4)(1 / 6)=9 / 24, \quad E\left(V_{a}\right)=1 / 4$

For threshold under 0: $\quad \mathrm{p}=5 / 9, \quad \mathrm{u}_{\mathrm{a}} / \mathrm{n}_{\mathrm{a}}=(10 / 4)(1 / 5)=10 / 20, \quad \mathrm{E}\left(\mathrm{V}_{\mathrm{a}}\right)=10 / 36$

For threshold under 1/4: $\quad \mathrm{p}=4 / 9, \quad \mathrm{u}_{\mathrm{a}} / \mathrm{n}_{\mathrm{a}}=(10 / 4)(1 / 4)=10 / 16, \quad \mathrm{E}\left(\mathrm{V}_{\mathrm{a}}\right)=10 / 36$

For threshold under 1/2: $\quad \mathrm{p}=3 / 9, \quad \mathrm{u}_{\mathrm{a}} / \mathrm{n}_{\mathrm{a}}=(9 / 4)(1 / 3)=9 / 12, \quad \mathrm{E}\left(\mathrm{V}_{\mathrm{a}}\right)=1 / 4$

For threshold under 3/4: $\quad p=2 / 9, \quad u_{a} / n_{a}=(7 / 4)(1 / 2)=7 / 8, \quad E\left(V_{a}\right)=7 / 36$

For threshold under 1: $\quad \mathrm{p}=1 / 9, \quad \mathrm{u}_{\mathrm{a}} / \mathrm{n}_{\mathrm{a}}=1, \quad \mathrm{E}\left(\mathrm{V}_{\mathrm{a}}\right)=1 / 9$

For threshold under 5/4: $\quad \mathrm{p}=0, \quad \mathrm{u}_{\mathrm{a}} / \mathrm{n}_{\mathrm{a}}=0, \quad \mathrm{E}\left(\mathrm{V}_{\mathrm{a}}\right)=0$

Expected utility is a maximum when the threshold is close to $u_{i}=0, n_{a}=(n-1) / 2$. This agrees with the former analysis by Smith since the threshold is placed at the mean. The maximum value of expected utility can be made to occur arbitrarily close to a threshold of zero by increasing $\mathrm{n}$. The graph is as follows:

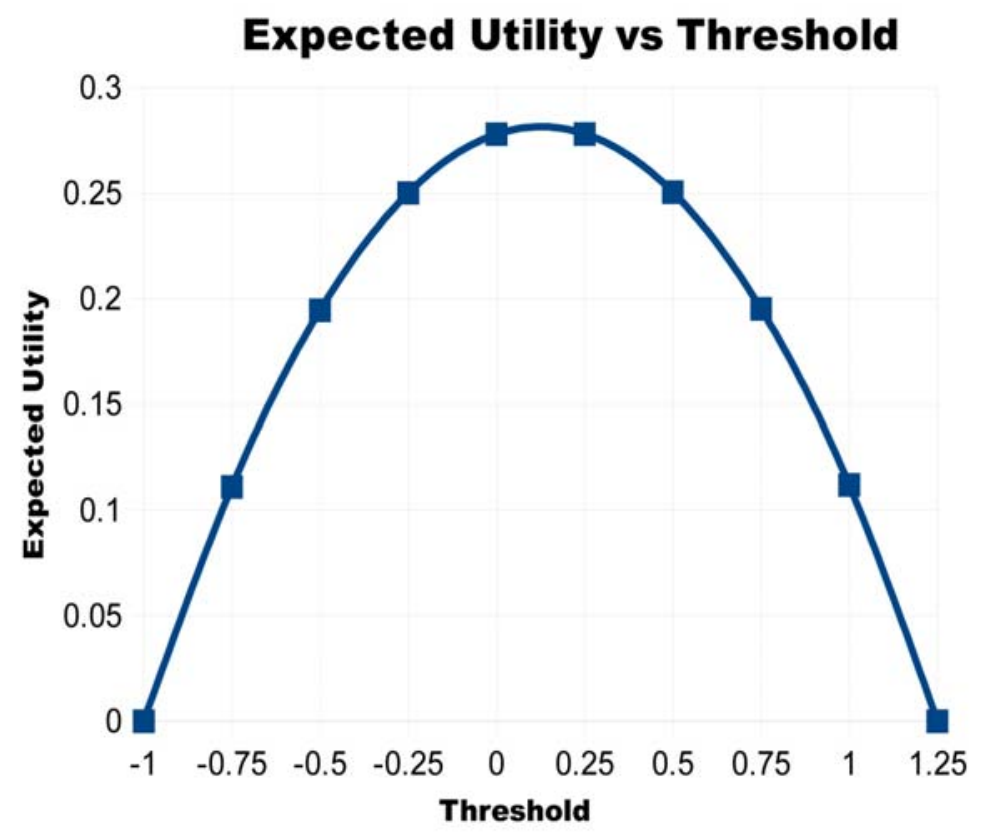




\section{Expected Utility vs Threshold for $\mathbf{m}=\mathbf{2}$}

Let us consider the case of a winning set of just 2 members, $m=2$. The threshold should be able to be raised from near the average of the individual citizen's ratings since the voter is more likely to get an outcome closer to their most preferred outcome. We proceed to find the best or optimal placement of the threshold.

According to the formula,

$$
\begin{aligned}
\mathbf{p} & =1-\frac{\left(\mathbf{n}-\mathbf{n}_{\mathrm{a}}\right)}{\left(\begin{array}{c}
\mathbf{n} \\
2
\end{array}\right)} \\
& =1-\frac{\left(\mathbf{n}-\mathbf{n}_{\mathrm{a}}\right)\left(\mathbf{n}-\mathbf{n}_{\mathrm{a}}-1\right)}{\mathbf{n}(\mathbf{n}-1)}
\end{aligned}
$$

\section{$p=1-\left[\left(n-n_{a}\right) / n\right]\left[\left(n-1-n_{a}\right) /(n-1)\right]=1-\left[1-\left(n_{a} / n\right)\right]\left[1-n_{a} /(n-1)\right]$}

For the set $u_{i} \in\{-1,-3 / 4,-1 / 2,-1 / 4,0,1 / 4,1 / 2,3 / 4,1)$, we have

$\begin{array}{llll}\text { For threshold under }-1: & \mathrm{p}=1, & \mathrm{u}_{\mathrm{a}} / \mathrm{n}_{\mathrm{a}}=0, & \mathrm{E}\left(\mathrm{V}_{\mathrm{a}}\right)=0 \\ \text { For threshold under }-3 / 4: & \mathrm{p}=1, & \mathrm{u}_{\mathrm{a}} / \mathrm{n}_{\mathrm{a}}=1 / 8, & \mathrm{E}\left(\mathrm{V}_{\mathrm{a}}\right)=.125 \\ \text { For threshold under }-1 / 2: & \mathrm{p}=70 / 72, & \mathrm{u}_{\mathrm{a}} / \mathrm{n}_{\mathrm{a}}=(7 / 4)(1 / 7)=1 / 4, & \mathrm{E}\left(\mathrm{V}_{\mathrm{a}}\right)=.243 \\ \text { For threshold under }-1 / 4: & \mathrm{p}=66 / 72, & \mathrm{u}_{\mathrm{a}} / \mathrm{n}_{\mathrm{a}}=(9 / 4)(1 / 6)=9 / 24, & \mathrm{E}\left(\mathrm{V}_{\mathrm{a}}\right)=.344 \\ \text { For threshold under } 0: & \mathrm{p}=60 / 72, & \mathrm{u}_{\mathrm{a}} / \mathrm{n}_{\mathrm{a}}=(10 / 4)(1 / 5)=10 / 20, & \mathrm{E}\left(\mathrm{V}_{\mathrm{a}}\right)=.417 \\ \text { For threshold under } 1 / 4: & \mathrm{p}=52 / 72, & \mathrm{u}_{\mathrm{a}} / \mathrm{n}_{\mathrm{a}}=(10 / 4)(1 / 4)=10 / 16, & \mathrm{E}\left(\mathrm{V}_{\mathrm{a}}\right)=.451 \\ \text { For threshold under } 1 / 2: & \mathrm{p}=42 / 72, & \mathrm{u}_{\mathrm{a}} / \mathrm{n}_{\mathrm{a}}=(9 / 4)(1 / 3)=9 / 12, & \mathrm{E}\left(\mathrm{V}_{\mathrm{a}}\right)=.438 \\ \text { For threshold under 3/4: } & \mathrm{p}=30 / 72, & \mathrm{u}_{\mathrm{a}} / \mathrm{n}_{\mathrm{a}}=(7 / 4)(1 / 2)=7 / 8, & \mathrm{E}\left(\mathrm{V}_{\mathrm{a}}\right)=.365 \\ \text { For threshold under 1: } & \mathrm{p}=16 / 72, & \mathrm{u}_{\mathrm{a}} \mathrm{n}_{\mathrm{a}}=1, & \mathrm{E}\left(\mathrm{V}_{\mathrm{a}}\right)=.222 \\ \text { For threshold under 5/4: } & \mathrm{p}=0, & \mathrm{u}_{\mathrm{a}} / \mathrm{n}_{\mathrm{a}}=0, & \mathrm{E}\left(\mathrm{V}_{\mathrm{a}}\right)=0\end{array}$

Here are the graphs for $\mathrm{m}=1$ and 2 : 


\section{Expected Utility vs Threshold}

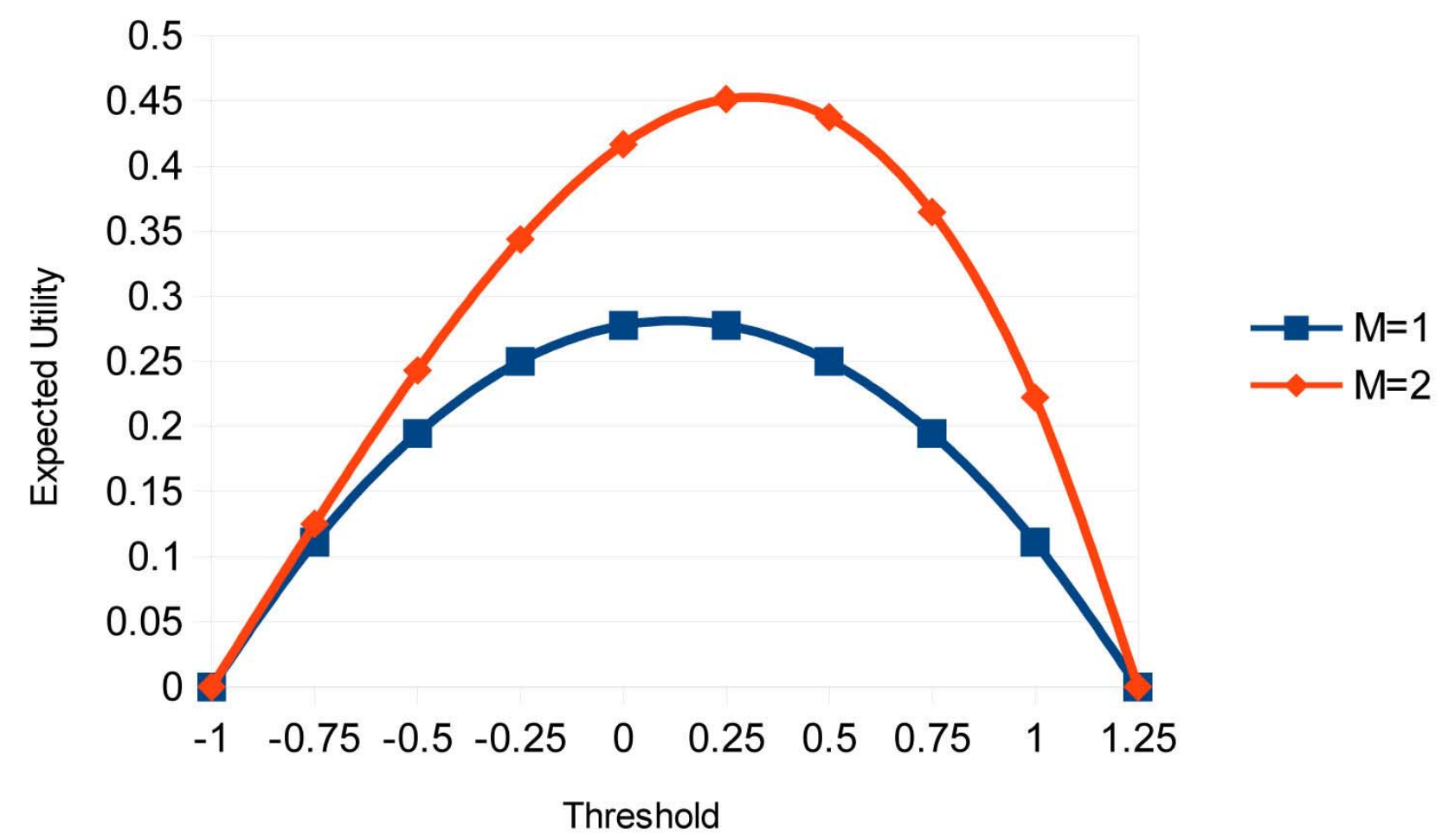

We can see that the peak has shifted to the right and upwards indicating that the threshold for which expected average utility is maximum has shifted up towards greater utilities and the expected average utility at that threshold is greater.

As $m$ increases, the individual under consideration should derive increased utility or satisfaction from the winning set since one or more of their above threshold candidates are more likely to become part of the winning set $\mathrm{W}$.

\section{Expected Utility vs Threshold for Higher Values of $\mathrm{m}$}

Now we increase the data set as follows

$$
\mathrm{u}_{\mathrm{i}} \in\{-1,-.95,-.9, \ldots,-.05,0, .05, \ldots, .9, .95,+1\}
$$

The graph is the following: 


\section{Expected Utility vs Threshold}

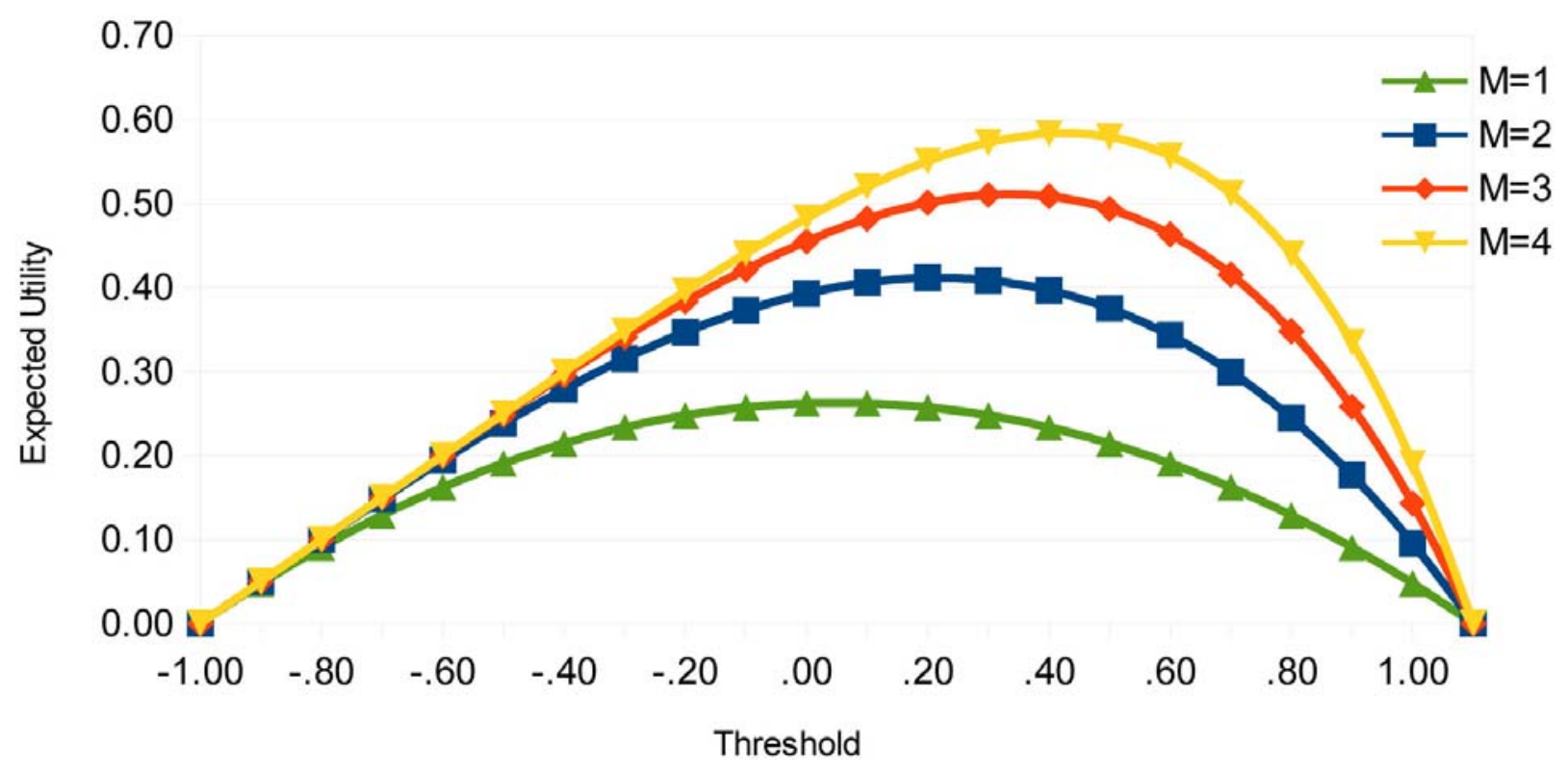

\section{For higher values of m, please see Appendix 3.}

\section{$\underline{\text { Summary and Conclusions }}$}

We have demonstrated a method for choosing candidates in a multi-winner election or for choosing a set of worker-consumer bundles from a larger set of bundles. The method generalizes from the political case to the economic case. In each case a winning set, $\mathrm{W}$, is chosen from a larger set, $\mathrm{S} . \mathrm{W} \subset \mathrm{S}$. $|\mathrm{W}|<|\mathrm{S}|$.

Let $\mathrm{m}=$ the size of the winning set $=|\mathrm{W}|, \mathrm{p}_{\mathrm{i}}=$ the probability of winning for each of $\mathrm{n}$ candidates and $u_{i}$, a real number $\left(-1 \leq u_{i} \leq+1\right)$, the utility associated with each candidate for a particular voter/worker-consumer. $\mathrm{n}_{\mathrm{a}}$ is the number of above threshold utilities and $\mathrm{u}_{\mathrm{a}}$ is their sum. No knowledge of the statistics is assumed. We let $\mathbf{p}$ equal the probability that at least one of the above threshold candidates is in the winning set. A threshold is placed in such a way that those candidates above threshold are given an approval or EV-3 style vote of +1 , and those candidates below threshold are given an approval or EV-3 style vote of -1 . Candidates falling on or near the threshold are given an EV-3 style vote of 0 . 
The threshold is placed so as to maximize the expected value of utility for the set of candidates above threshold for each individual voter. After the approval style votes are tallied over all voters, the candidates with the m highest totals are chosen to be in the winning set. The method for determining the threshold has been graphically illustrated for a uniform distribution of candidates with associated utilities over the range from -1 to +1 . The method is easily generalized for any distribution of candidates and utilities.

Thresholds can be determined in advance by sophisticated computer algorithms. The computations in and of themselves should not be a hindrance to the implementation of this system.

Warren D. Smith ${ }^{16}$ has proven that, for the case of one possible realized outcome $(m=1)$, the best choice of threshold for each individual is the arithmetic mean utility of the sincere preference ratings over all the candidates. Therefore, range/approval hybrid voting has been proven to be optimal for this case. This paper generalizes that result for $\mathrm{m}>1$. We show how to optimally compute the position of the threshold. Then the sincere preference ratings can be converted to approval style or evaluative EV-3 style votes.

Since the optimal strategy for each individual voter is known, strategy can be taken out of the hands of individuals and placed in the system itself which applies the optimal strategy for each individual to their sincere preference ratings before their final votes are added to the tally. Any gains from strategizing are thus distributed equally throughout the electorate. This makes it impossible for an individual to gain anything by voting insincerely.

We have shown that both political and economic utility or satisfaction increase as the size of the winning set, $|\mathrm{W}|$ increases. We show in Appendix 1 that for any given threshold, $\mathrm{T}(-1 \leq \mathrm{T} \leq+1)$, if we increase the number of alternatives, $\mathrm{m}$, the expected value of utility increases.

We show in Appendix 2 that for a uniform distribution of candidates with corresponding utilities and a given threshold index, $\mathrm{t},(0 \leq \mathrm{t} \leq \mathrm{n}-1), \mathrm{E}\left(\mathrm{V}_{\mathrm{a}}\right)$ can be maximized by increasing $\mathrm{m}$ and the maximum value of $\mathrm{E}\left(\mathrm{V}_{\mathrm{a}}\right)$ is equal to $\mathrm{t} /(\mathrm{n}-1)$ at that threshold.

We show in Appendix 3 a graph depicting expected utility vs threshold for values of $\mathrm{m}$ ranging from 1 to 16 .

This theory represents a meta-theory from which both political and economic solutions can be derived and unifies the split in social choice theory between political and economic decision making. 
Arrow's Impossibility Theorem gave a theoretically endorsed superiority to winner-takeall, majority rule, single member districts. By the same token there was a tacit endorsement of the capitalist economic system since, according to the Theorem, there is no rational method of choosing or assigning economic outcomes based on individual inputs. This paper challenges those assumptions and asserts that there is a rational method for aggregating individual choices into rational social decisions.

We envision a system wherein the individual voter expresses their utilitarian preference ratings over the candidate set and the system takes these and computes the approval style votes. The voters have no incentive to misrepresent their preference ratings knowing that the system will compute their approval style votes based on mnaximizing their individual utility over the candidate set. In Arrow's discussion of his Independence of Irrelevant Alternatives (IIA) condition, he posits a situation in which the social ordering changes if one candidate drops out of the race. If that happens in the method presented herein, the system will simply recompute the individual thresholds based on the input data which is assumed not to change whether or not a candidate drops out. For instance, if a voter rates candidate $\mathrm{A}$ as .8 on a scale from 0 to 1 , he will still rate that candidate .8 even if candidate B drops out of the race. The system would just take the originally submitted utilitarian date and recompute to find the optimum outcome. This makes Arrow's IIA condition irrelevant just as Lehtinen has shown.

\section{Appendix}

\section{Appendix 1:}

Theorem 1: For any given threshold, $\mathrm{T}(-1 \leq \mathrm{T} \leq+1)$, if we increase the number of alternatives, $\mathrm{m}$, the expected value of utility increases. Proof by induction:

$\mathrm{E}\left(\mathrm{V}_{\mathrm{a}}\right)=\mathrm{p}\left(\mathrm{u}_{\mathrm{a}} / \mathrm{n}_{\mathrm{a}}\right)$

For a given threshold, $\mathrm{u}_{\mathrm{a}} / \mathrm{n}_{\mathrm{a}}$ is constant. Therefore, $\mathrm{E}\left(\mathrm{V}_{\mathrm{a}}\right)$ depends only on $\mathrm{p}$ if $\mathrm{m}$ increases.

$$
\begin{aligned}
& \mathrm{p}=1-\left[1-\left(\mathrm{n}_{\mathrm{a}} / \mathrm{n}\right)\right]\left[1-\mathrm{n}_{\mathrm{a}} /(\mathrm{n}-1)\right] \ldots\left[1-\mathrm{n}_{\mathrm{a}} /(\mathrm{n}-\mathrm{i})\right] \ldots\left[1-\mathrm{n}_{\mathrm{a}} /(\mathrm{n}-\mathrm{m}+1)\right] \\
& 1 \leq \mathrm{n}_{\mathrm{a}} \leq \mathrm{n}, 0 \leq \mathrm{i} \leq \mathrm{m}-1
\end{aligned}
$$$$
\text { For } \mathrm{m}=1, \mathrm{p}=\left[1-\left(\mathrm{n}_{\mathrm{a}} / \mathrm{n}\right)\right]
$$ 
For $m=2, p=1-\left[1-\left(n_{a} / n\right)\right]\left[1-n_{a} /(n-1)\right]$

$\left[1-\left(n_{a} / n\right)\right]\left[1-n_{a} /(n-1)\right]<\left[1-\left(n_{a} / n\right)\right]$

since when two fractions are multiplied together, the result is less than either fraction.

Therefore, $\mathrm{p}$ for $\mathrm{m}=2$ is greater than $\mathrm{p}$ for $\mathrm{m}=1$ and $\mathrm{E}\left(\mathrm{V}_{\mathrm{a}}\right)$ for $\mathrm{m}=2$ is greater than $\mathrm{E}\left(\mathrm{V}_{\mathrm{a}}\right)$ for $m=1$.

Therefore, the theorem holds for $\mathrm{m}=1$.

Now assume that the theorem is true for $m=m^{\prime}>1$

Then $p=1-\left[1-\left(n_{a} / n\right)\right]\left[1-n_{a} /(n-1)\right] \ldots\left[1-n_{a} /\left(n-m^{\prime}+1\right)\right]$

We show that it is true for $\mathrm{m}^{\prime}+1$

$p^{\prime}=1-\left[1-\left(n_{a} / n\right)\right]\left[1-n_{a} /(n-1)\right] \ldots\left[1-n_{a} /\left(n-\left\{m^{\prime}+1\right\}+1\right)\right]$

Since $\left[1-n_{a} /\left(n-\left\{m^{\prime}+1\right\}+1\right)\right]$ is a fraction and a fraction times a fraction is less than the original fraction, $\mathrm{p}^{\prime}>\mathrm{p}$ and $\mathrm{E}^{\prime}\left(\mathrm{V}_{\mathrm{a}}\right)>\mathrm{E}\left(\mathrm{V}_{\mathrm{a}}\right)$ when $\mathrm{m}^{\prime}>\mathrm{m}$ at the same threshold, $\mathrm{t}$.

\section{Appendix 2:}

Theorem 2: For a uniform distribution of candidates with corresponding utilities and a given threshold index, $t,(0 \leq t \leq n-1), E\left(V_{a}\right)$ can be maximized by increasing $m$ and the maximum value of $E\left(V_{a}\right)$ is equal to $t /(n-1)$ at that threshold.

As the threshold increases from 0 , for a given $\mathrm{m}, \mathrm{u}_{\mathrm{a}}$ increases.

$\mathrm{t}=\mathrm{n}-\mathrm{n}_{\mathrm{at}}$

$\mathrm{n}_{\mathrm{at}}=$ na at threshold index $\mathrm{t}$

$0 \leq \mathrm{u}_{\mathrm{a}} \leq 1$

Let $\mathbf{u}_{\mathrm{at}}$ represent $\mathbf{u a}$ at threshold $\mathbf{t}, \mathbf{u}_{\mathrm{at}} \in\left\{\mathbf{u}_{\mathrm{a} \mathbf{0}}, \mathbf{u}_{\mathrm{a} 1}, \mathbf{u}_{\mathrm{a} 2}, \ldots, \mathbf{u}_{\mathrm{an}}\right\}$

$\mathbf{u}_{\mathrm{a} 0}=\mathbf{u}_{\mathrm{an}}=\mathbf{0}$ by definition. 


$$
\begin{aligned}
\mathbf{E}_{a t} & =p_{a t}\left(u_{a t} / n a t\right) \\
p_{a t} & =1-\prod_{i=0}^{m-1} \frac{(t-i)}{(n-i)} \\
\frac{u_{a t}}{n_{a t}} & =\left(\frac{1}{n-t}\right) \sum_{i=1}^{t}\left[1-\frac{2(i-1)}{n-1}\right] \\
= & \left.\frac{1}{n-t}\right)\left[t-\sum_{i=1}^{t}\left\{\frac{2(i-1)}{n-1}\right\}\right] \\
= & \left.\frac{t}{n-t}-\left[\frac{2}{(n-t)(n-1)}\right] \mid \sum_{i=1}^{t}(i-1)\right] \\
= & \frac{t}{n-t}-\left[\frac{2}{(n-t)(n-1)}\right]\left[\frac{t(t+1)}{2}-t\right] \\
& =\frac{t}{n-t}-\left[\frac{t(t-1)}{(n-t)(n-1)}\right] \\
& =\frac{t(n-1)-t(t-1)}{(n-t)(n-1)} \\
& t
\end{aligned}
$$

Therefore, 


$$
E_{a t}=p_{a t}\left(\frac{u_{a t}}{n_{a t}}\right)=\left[1-\left(\frac{t}{n}\right)\left(\frac{t-1}{n-1}\right) \ldots\left(\frac{t-i}{n-i}\right) \ldots\left(\frac{t-m+1}{n-m+1}\right)\right]\left[\frac{t}{n-1}\right]
$$

$\mathbf{t}<\mathbf{n}, \mathbf{m}<\mathbf{n}$

The second term in $\mathbf{p}_{\text {at }}$ can be driven to zero by increasing $\mathrm{m}$.

If $m$ is sufficiently great, $\mathbf{t} \rightarrow(\mathbf{n}-\mathbf{1}), \mathbf{p}_{\mathbf{a t}} \rightarrow \mathbf{1}$,

$$
\frac{\mathbf{u}_{\mathrm{at}}}{\mathbf{n}_{\mathrm{at}}} \longrightarrow \mathbf{1}
$$

and $\mathbf{E}_{\text {at }}=\mathbf{t} /(\mathbf{n}-\mathbf{1})$.

\section{Appendix 3: Graph for Higher Values of $m$}

Expected Utility vs Threshold

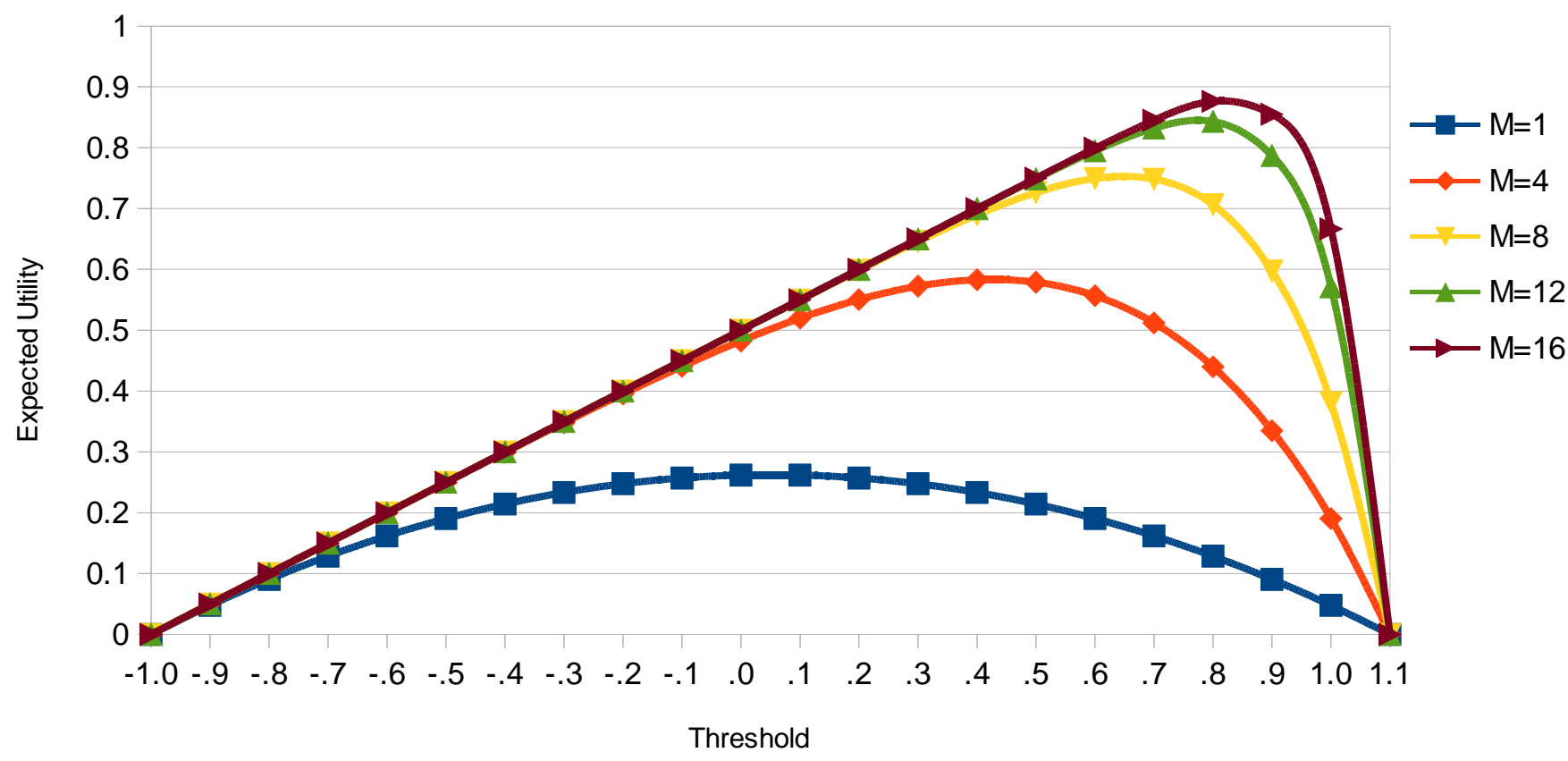




\section{$\underline{\text { References }}$}

1. Arrow, Kenneth J. (1951), Social Choice and Individual Values, Yale University Press, p. 1.

2. Lehtinen, Aki (2015), "A welfarist critique of social choice theory: interpersonal comparisons in the theory of voting," Erasmus Journal For Philosophy And Economics, Vol. 8, No. 2, p. 77.

3. Gibbard, A. (1973), "Manipulation of voting schemes: a general result," Econometrica, Vol. 41, No. 4, pp. 587-601.

4. Satterthwaite, M. A. (1975), "Strategy-proofness and Arrow's Conditions: Existence and Correspondence Theorems for Voting Procedures and Social Welfare Functions," Journal of Economic Theory, 10, pp. 187-217.

5. Smith, Warren, http://www.rangevoting.org/RVstrat3.html\#conc

6. Elkind, E., Faliszewski, P., Skowron, P. et al. (2017), "Properties of multiwinner voting rules," Social Choice and Welfare, Vol. 48, Issue 3, pp 599-632.

7. Faliszewski, Piotr, et al. (2017), "Multiwinner voting: A new challenge for social choice theory." Trends in computational social choice, Vol. 74.

8. Aziz, Haris, et al. (2017), "Justified representation in approval-based committee voting," Social Choice and Welfare, Vol.48, Issue.2, pp. 461-485.

9. Kilgour, D. Marc. (2010), "Approval balloting for multi-winner elections," Handbook on approval voting, Springer, Berlin, Heidelberg, pp. 105-124.

10. Fishburn, Peter and Saša Pekeč, "Approval Voting Approach to Subset Selection," http://people.duke.edu/ pekec/AVsubsetchoice.pdf

11. Meir, Reshef et. al. (2008), "A Broader Picture of the Complexity of Strategic Behavior in Multi-Winner Elections" Proceedings of the 7th international joint conference on Autonomous agents and multiagent systems, Vol. 2, pp. 991-998.

12. Brams, Steven J. and Fishburn, Peter C. (1983), Approval Voting, BirkhauserBoston.

13. Lehtinen, Aki (2011), "A Welfarist Critique of Social Choice Theory," Journal of Theoretical Politics, Vol. 23, No. 3, pp. 359-381.

14. Harsanyi, John C. (1955), "Cardinal Welfare, Individualistic Ethics, and Interpersonal Comparisons of Utility", The Journal of Political Economy, Vol. 63, Issue 4, pp. 309-321.

15. Risse, M. (2002), "Harsanyi's 'Utilitarian Theorem' and Utilitarianism," Nous, Vol. 36, No. 4, pp. 550-577.

16. Niemi, Richard G. (1984) "The Problem of Strategic Behavior under Approval Voting," The American Political Science Review, Vol. 78, No. 4, pp. 952-958.

17. Cox, Gary W. (1984), "Strategic Electoral Choice in multi-winner Districts: Approval Voting in Practice?*", American Journal of Political Science, Vol. 28, No. 4, pp. 732-738. 
18. Binmore, K. (2009), "Interpersonal Comparison of Utility," The Oxford Handbook of Philosophy of Economics.

19. Hillinger, C. (2005), "The Case for Utilitarian Voting," Homo Oeconomicus, Vol.22, No. 3.

20. Hillinger, C. (2004), "Utilitarian Collective Choice and Voting," Online at http://epub.ub.uni-muenchen.de/473/

21. Mucsi, Lorinc (2015), "A Discussion on the Merits of Evaluative Voting," Western Undergraduate Economics Review, pp. 21-34.

22. Hillinger, Claude (2004), "Voting and the Cardinal Aggregation of Judgements," University of Munich: Department of Economics 9, pp. 1-25. http://epub.ub.unimuenchen.de/353/1/hillinger_voting.pdf

23. Lehtinen, Aki (2007), "The Welfare Consequences of Strategic Behaviour Under Approval and Plurality Voting," European Journal of Political Economy, Vol. 24, No. 3, pp. 688-704.

24. Gendin, Sidney. (1994), "Why Arrow's Impossibility Theorem Is Invalid," Journal of Social Philosophy, Vol. 25 No. 1, pp. 144-159.

25. Smith, Warren, http://www.rangevoting.org/RVstrat3.html\#conc

26. Smith, Warren, http://rangevoting.org/BayRegDum.html

27. http://www.rangevoting.org/

28. Brams, S.J. and Fishburn, P.C. (2005) "Going from theory to practice: the mixed success of approval voting," Social Choice and Welfare, Vol. 25 pp. 457-474. 